\title{
Modification of Regeneration Polyurethane by Blend with Ternary Nylon
} Chun-Fa OUYANG ${ }^{\mathrm{a}, *}$, Xiao-Ting $\mathrm{JI}^{\mathrm{b}}$, Qun $\mathrm{GAO}^{\mathrm{c}}$, Chun-Ye $\mathrm{XU}^{\mathrm{d}}$

\author{
School of Material Science \& Engineering, Shanghai Institute of Technology, Shanghai, 201418, \\ China \\ aouyoung_0916@163.com, bjxt906869@163.com, cwityy@sit.edu.cn, d361076096@qq.com \\ *Corresponding author
}

Keywords: Regeneration Polyurethane, Ternary Nylon, Modified, Alcoholysis.

\begin{abstract}
Regeneration polyurethane was completely originated from waste polyurethane fibers by solid-phase alcoholysis under dynamic shearing condition, and then modified with ternary nylon. The effect of ternary nylon on the process of solid-phase alcoholysis has been investigated by infrared spectrum and torque rheometry. The results showed that the ternary nylon has strong affinity with the regeneration polyurethane due to hydrogen bonding taking place among them. The crystalline texture of regeneration polyurethane was changed via modified with ternary nylon, which was detected by XRD. The modified regeneration polyurethane was vulcanized by dicumyl peroxide. The mechanical properties and dynamic mechanics performance of regeneration polyurethane rubber were changed by ternary nylon. The mechanics performance results showed increasing hardness and tear strength of regeneration polyurethane rubber with increasing ternary nylon addition. With growing amount of ternary nylon, the tensile strength and abrasion loss of regeneration polyurethane rubber firstly increased and then decreased. When ternary nylon added, the glass-transition temperature of regeneration polyurethane rubber went up, and the $\tan \delta$ of regeneration polyurethane rubber declined. With ternary nylon added, the glass-transition temperature of regeneration polyurethane rubber was increased, and the $\tan \delta$ of regeneration polyurethane rubber was declined.
\end{abstract}

\section{Introduction}

Polyurethane fiber, usually reacted by polyester polyols, polyether polyols or polyester mix-polyether polyol et al and isocyanate [1]. Since the 20th century, with the constant development of the economy, production of polyurethane fiber is rapidly expanding in China and other emerging markets. In 2014, the National Bureau of Statistics and the Customs show that production of polyurethane fiber is about 391,100 tons. So much production will generate a large amount of scrap and scrap material aging. Therefore, there are significant economic and social benefits to find a reasonable way to make use of waste polyurethane fiber, to rationalize the use of resources.

Currently, methods for chemical recycling of polyurethane include alcoholysis, glycolysis, hydrolysis, aminolysis [2-5]. And most of the recycling works on polyurethanes have focused on polyurethane foams in order to obtain polyols for the production of new polyurethane material. In this paper, regeneration polyurethane is obtained from waste polyurethane fibers via solid-phase alcoholysis.

At present, there are many studies on nylon/polyurethane blends. Zhang [6] et al prepared the PA1010/TPU blends by melt blending. The results showed that the addition of TPU could promote the crystallization of PA1010, but not affect the crystallization mechanism. Hou [7] et al made the preparation and characterization of thermoplastic polyurethane elastomer and polyamide 6 blends. Compared with nylon, ternary nylon easily blended with rubber because of the low melting point. In this paper, we used ternary nylon modified regeneration polyurethane and then prepared millable urethane rubber. In addition, the mechanical properties of millable urethane rubber (MPU) with different concentrations of ternary nylon were investigated. 


\section{Experiment}

\section{Materials}

Industrial scrap of polyurethane fibers was used as degradation materials, supplied by the Hyosung Spandex Co., Ltd. The fibers were mostly based on 4, 4-diphenyl methane diisocyanate and polyethylene tetrahydrofuran ether.

Polyethylene glycol 6000 (PEG6000), precipitated silica, calcium oxide (CaO), dicumyl peroxide (DCP) and triallyl isocyanurate (TAIC) were from Sinopharm Chemical Regent Co., Ltd. PEG6000 was used as alcoholysis agent and $\mathrm{CaO}$ was used as catalytic agent in this work. Precipitated silica was used as reinforcing agent and dried at $100^{\circ} \mathrm{C}$ for $24 \mathrm{~h}$ before use. Dicumyl peroxide was used as vulcanizing agent and TAIC was used as assistant crosslinker.

Ternary nylon (PA6/PA66/PA1010 =10/20/70) was purchased in the Shanghai composite materials co., LTD. The melting point of ternary nylon was $140-160 \quad{ }^{\circ} \mathrm{C}$.

\section{The Preparation and Modification of Regeneration Polyurethane}

A RM-200C HAPROTM rheometer (Harbin hapro electrical technology Co., Ltd, China) was used for alcoholysis process.

The optimal reaction conditions for alcoholysis have been determined by experiment. Thus in this paper all the alcoholysis processing conditions were kept at temperature of $190{ }^{\circ} \mathrm{C}$, a rotor speed of $30 \mathrm{rpm}$, and the processing time was based on the torque-time curve. The waste polyurethane fiber was mixed with PEG6000 of 5 phr, CaO of 2 phr and ternary nylon in the rheometer. Changing the proportion of ternary nylon, the different regeneration polyurethane (RPU) was gained.

\section{The Preparation of Millable Polyurethane Rubbers}

The manufacturing process of millable polyurethane rubbers included mastication, compounding and vulcanization. Initially, modified RPU (100 phr) was masticated in a laboratory roller mill for 5 min. After then, precipitated silica (30 phr) was added and the mixing process was carried on for a few minutes. Thereafter, DCP and TAIC was added and mixed with the blends for a few minutes to ensure homogeneous mixing. In the vulcanization process, the vulcanized millable polyurethane rubber was prepared by compression-molded under a pressure up to $180 \mathrm{~kg} / \mathrm{cm}^{2}$ at a cure temperature of $160{ }^{\circ} \mathrm{C}$. The cure time of vulcanization process completion was the time for $90 \%$ cure, which was determined by JC-2000E Moving Die Rheometer.

\section{Results and Discussion}

\section{The Influence of Ternary Nylon on Alcoholysis Process}

The curve of torque-time during the degradation process of polyurethane fibers is presented in Fig.1. The torque decreased rapidly because the polyurethane fibers transformed into powder under shearing force and high temperature in the first ten minutes. Then the torque rose slowly to attain the pinnacle result from alcoholysis reactions of polyurethane. The initial stage of the experiment, the torque increased gradually. In this process, under shear stress, intermolecular and intramolecular forces in the waste polyurethane fiber were weakened, and the molecular structure was destroyed. Then waste polyurethane fiber begins to degrade as a result of high temperature, alcoholysis agent, catalyst and the like. At the same time the material temperature gradually increased, ternary nylon gradually dispersed. Therefore, the torque was increased to the highest point after the start of fall. 


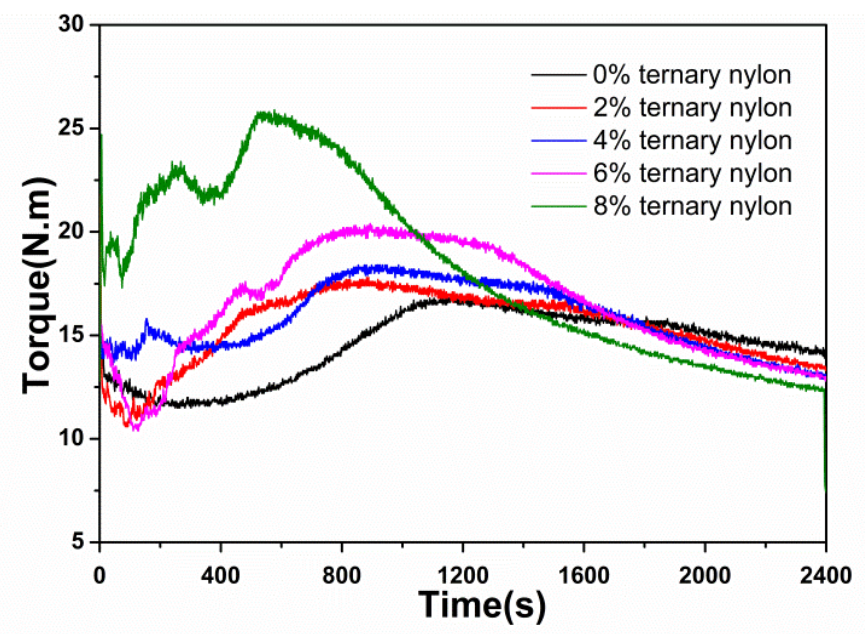

Fig.1 Graph of the rheological torque-time curve of alcoholysis process with different content of ternary nylon

\section{The Characteristics of RPU Modified with the Ternary Nylon}

Fig.2 (A) showed IR spectra of polyurethane fiber and RPU modified with the 8\% of ternary nylon. Fig.2 (B) shows details of the IR spectra of polyurethane fiber and RPU modified with the $8 \%$ of ternary nylon between 800 and $1800 \mathrm{~cm}^{-1}$. The absorption peak observed at $1735 \mathrm{~cm}^{-1}$ can be assigned to urethane groups and the absorption band observed at $1640 \mathrm{~cm}^{-1}$ can be assigned to urea groups. The IR absorbance peaks of urea and urethane functional group in both regeneration polyurethane modified with the ternary nylon and polyurethane appeared at 1640 and $1735 \mathrm{~cm}^{-1}$, respectively, indicating that polyurethane fiber was partial degraded during the alcoholysis process. There were four new absorption bands appear at $3650 \mathrm{~cm}^{-1}$ in IR spectrum (Fig. 2A) and $1340 \mathrm{~cm}^{-1}$, $1273 \mathrm{~cm}^{-1}, 960 \mathrm{~cm}^{-1}$ in IR spectrum(Fig. 2B). Among them, absorption band at $3650 \mathrm{~cm}^{-1}$ was assigned to free $-\mathrm{OH}$ and absorption band at $960 \mathrm{~cm}^{-1}$ was assigned to $\mathrm{C}-\mathrm{O}$ in the polyol chain because of transesterification. The absorption peak at $1340 \mathrm{~cm}^{-1}$ and $1273 \mathrm{~cm}^{-1}$ corresponding to the $\mathrm{Ph}-\mathrm{NH}$ vibration in aromatic amine, which released by the urea group in the process of degradation. Additionally, absorption bands at 2940 and 2854cm-1 characteristic of bending vibrations of methylene groups in the regeneration polyurethane showed in Fig. 2. Hence, the dicumyl peroxide was used curing agent of regeneration polyurethane.

A

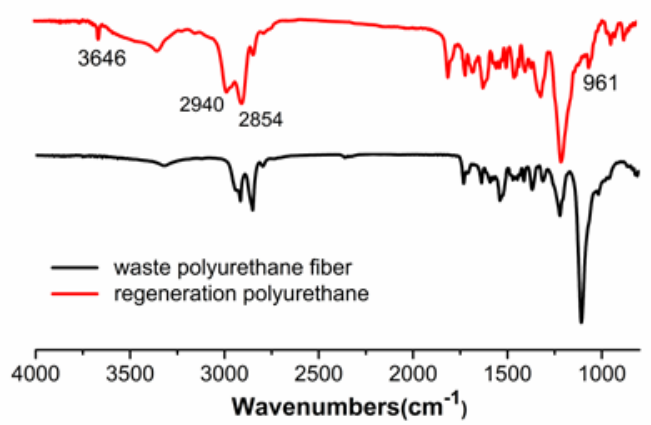

B

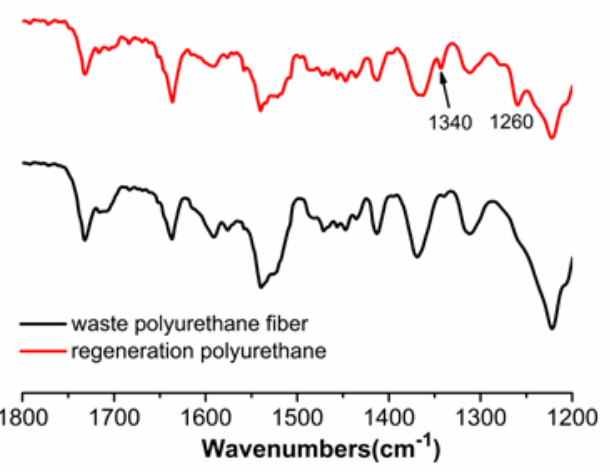

Fig.2 IR spectra of polyurethane fiber and regeneration polyurethane modified with the ternary nylon

At a temperature of $200^{\circ} \mathrm{C}$, waste polyurethane fiber mixed in the torque rheometer was named product A. For the same conditions, product B was obtained by waste polyurethane fiber mixed with $8 \%$ of the ternary nylon. The infrared spectrum of B and A were compared to research whether 
the ternary nylon has an effect on the polyurethane alcoholysis. In the infrared spectrum of product A, the absorption peak at $3318 \mathrm{~cm}^{-1}$ was assigned to the symmetric vibrational stretching of -NH group. The $-\mathrm{NH}$ group peak position was shifted to lower wave number region $\left(3297 \mathrm{~cm}^{-1}\right)$ in product $\mathrm{B}$, which indicated that the intermolecular hydrogen bonding was established between $\mathrm{H}-\mathrm{N}-\mathrm{C}=\mathrm{O}$ of ternary nylon and $-\mathrm{NH}$ of Product A. But the other absorption peak in the infrared spectrum of product A and B were same to each other. It was concluded that the ternary nylon has not effect on polyurethane fiber alcoholysis process, but the ternary nylon had strong affinity with the regeneration polyurethane due to hydrogen bonding taking place among them.

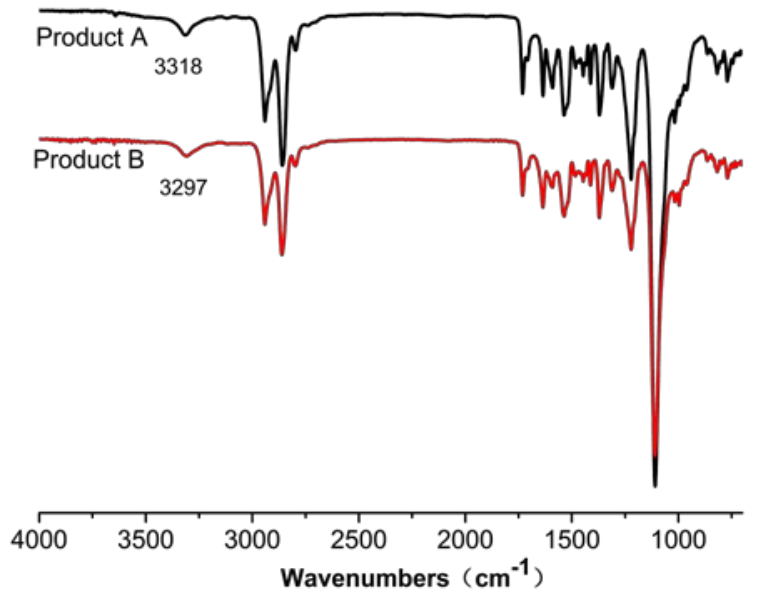

Fig.3 The IR spectra of product A and product B

\section{Microstructures of RPU Modified with the Ternary Nylon}

In the present study, X-ray diffraction pattern of RPU modified with the different concentration of ternary nylon were shown in Fig.4. Previous studies stated that the crystallinity of PU elastomers was provided by the soft segments [8]. So that crystallinity in the follow study project was due to soft segment and ternary nylon. The diffraction peak at $2 \theta=19.28^{\circ}$ corresponds to soft segment of RPU (Fig. 4). The increase in ternary nylon contents results to the intensity peak of soft segment was shifted to higher degree (towards right), indicating a slightly smaller inter domain spacing. This effect may be cause of the intermolecular hydrogen bonding was established between $\mathrm{H}-\mathrm{N}-\mathrm{C}=\mathrm{O}$ of ternary nylon and $-\mathrm{NH}$ of RPU. After modified with ternary nylon, a new diffraction peak at $2 \theta=23.28^{\circ}$ appeared in the diffraction pattern of RPU. Two peaks at $20.1^{\circ}$ and $23.7^{\circ}$ were characteristic basal reflections of nylon corresponding to $\alpha$-crystalline form. The results showed that the crystalline texture of RPU was changed by modified with ternary nylon, indicating that the RPU had better miscibility with ternary nylon.

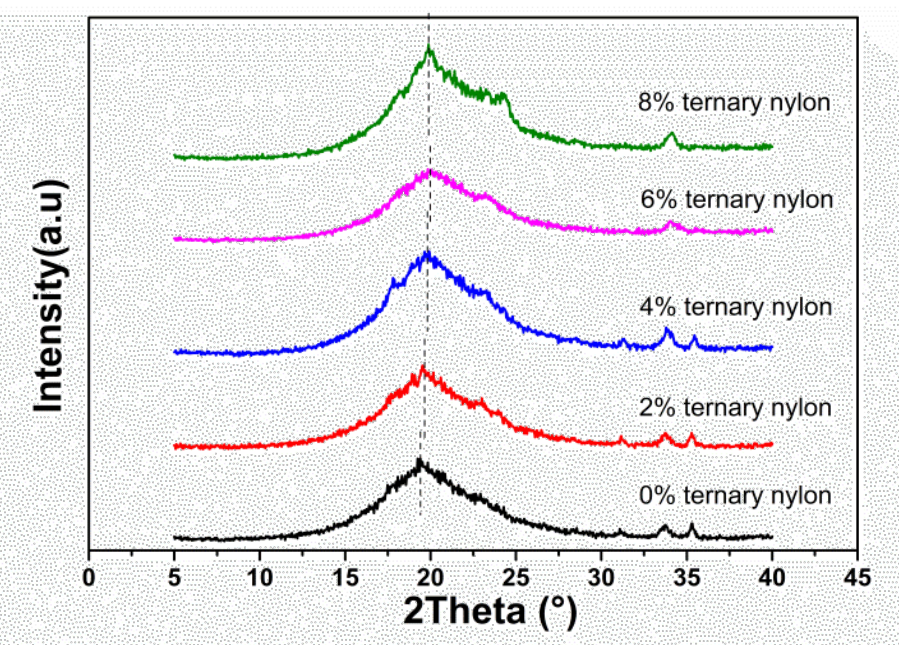

Fig.4 X-ray diffraction patterns of RPU modified with the ternary nylon 


\section{Dynamic Mechanical Properties}

DMA results for the regeneration millable polyurethane rubber (RMPUR) with different content of ternary nylon were shown in Fig. 5 . The peak appearing at about $-60^{\circ} \mathrm{C}$ corresponded to the glass transition of the RMPUR with no modified. After adding the ternary nylon, the glass transition temperature of the RMPUR was increased. Because of the intermolecular hydrogen bonding was established between $\mathrm{H}-\mathrm{N}-\mathrm{C}=\mathrm{O}$ of ternary nylon and $-\mathrm{NH}$ of RMPUR, which was hinder the molecular chain rotation. In the $\tan \delta$ curve of the RMPUR with no modified, besides the main $\tan \delta$ peak, a small shoulder peak was identified for the hard segments of RMPUR. This indicates that the micro-phase separation phenomenon exist in the RMPUR. With the loading amount of ternary nylon increased, the shape of $\tan \delta$ peak was altered, which indicate that the structure of the modified RMPUR was changed. Amazingly there was only one tan $\delta$ peak in the RMPUR with $6 \%$ ternary nylon, shows that the compatibility of RPU and ternary nylon was best in this ratio.
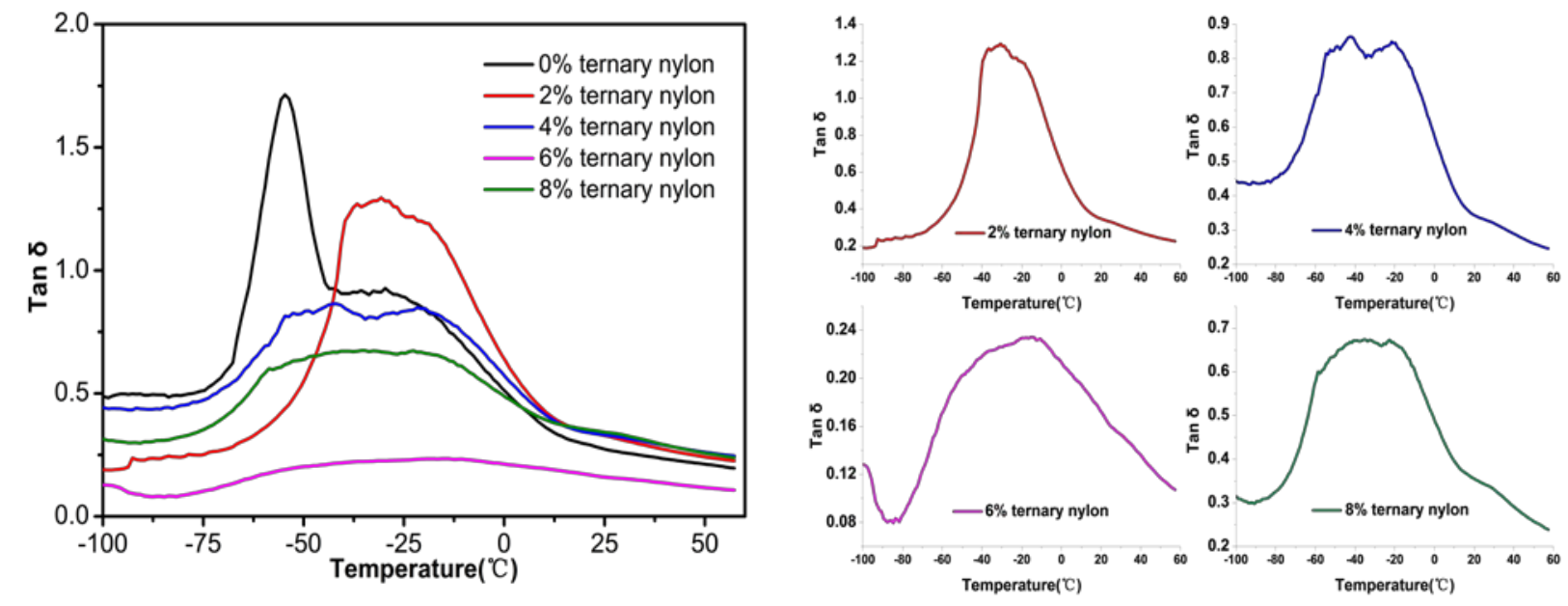

Fig.5 Temperature dependence of the damping behavior $(\tan \delta)$ of RMPUR with different content of ternary nylon

Under the action of alternating stress, for the materials with high $\tan \delta$, higher proportion of mechanical energy was converted to heat energy. As a result, the material was easy to occur prematurely aging and softening due to the temperature rising faster. With the amount of ternary nylon in the range from $2 \%$ to $6 \%$, the $\tan \delta$ of RMPUR decreased gradually. The reductions in $\tan$ $\delta$ may indicated that the anti-aging properties of RMPUR can be improved by modified with $6 \%$ ternary nylon.

\section{The Mechanical Properties of the RMPUR}

Mechanical properties of the RMPUR modified with different amount of ternary nylon are summarized in Table1. Firstly, the tensile strength of RMPUR significantly increased with ternary nylon content up to $4 \%$. It was attributed to the crystalline texture and structure of RMPUR was changed by modified with ternary nylon. When the loading amount of ternary nylon was more than $4 \%$, the tensile strength gradually decreased. The reductions in tensile strength may were due to poor dispersion of vulcanizing agent in the RMPUR. The hardness, tear strength and modulus at $100 \%$ strain of RMPUR were all increased with the loading amount of ternary nylon, due to the influence of polar groups (amide) in the ternary nylon. The Elongation at break reached a maximum value at $312.73 \%$ when the RMPUR modified with $8 \%$ of ternary nylon. As showed in Tab.1, the abrasion loss of RMPUR decreased to $0.0487 \mathrm{~cm}^{3}$ at $6 \%$ ternary nylon concentration. 
Tab.1 Mechanical Properties

\begin{tabular}{cccccc}
\hline Characteristics & \multicolumn{5}{c}{ Samples } \\
\cline { 2 - 6 } & $0 \%$ & $2 \%$ & $4 \%$ & $6 \%$ & $8 \%$ \\
\hline Hardness [Shore A] & 76 & 78 & 78 & 80 & 80 \\
Modulus at 100\% strain & 5.19 & 5.89 & 5.82 & 6.11 & 6.15 \\
Tensile strength [MPa] & 16.52 & 18.87 & 24.84 & 22.97 & 18.47 \\
Elongation at break [\%] & 262.01 & 259.88 & 312.73 & 268.87 & 257.71 \\
Tear strength [MPa] & 37.59 & 41.94 & 44.61 & 44.64 & 45.62 \\
Abrasion loss [cm ${ }^{3}$ ] & 0.0551 & 0.0513 & 0.0493 & 0.0487 & 0.0655 \\
\hline
\end{tabular}

\section{Conclusion}

The waste polyurethane fiber can be transformed to RPU by solid-phase alcoholysis based on mechanochemical reaction. The RPU mainly contained active hydrogen group such as urethane group, urea group and polyols. In this paper, the RPU was modified with different proportion of ternary nylon. The ternary nylon had strong affinity with the RPU due to hydrogen bonding taking place among them. The crystalline texture of RPU was changed by ternary nylon. The mechanical properties of RMPUR were improved via the modification of ternary nylon. Such as the tensile strength of RMPUR increased from 16.52 MPa to $24.84 \mathrm{MPa}$, the hardness increased from 76 to $80 \mathrm{~A}$ et al. The RMPUR modified with $6 \%$ ternary nylon, has better anti-aging properties and lower energy consumption. The most important point was that the whole production process was economic and environment-friendly.

\section{References}

[1] M.A. Invernale, Y. Ding, and G.A. Sotzing, ACS. Appl. Mater. Inter., 2(2010), 296-300.

[2] K.M. Zia, H. N. Bhatti, B.I. Ahmad, Methods for polyurethane and polyurethane composites, recycling and recovery: A review. React. Funct. Polym., 67(2007), 675-692.

[3] L. Liu, T. Lihu, W. Yongqiang, N. Yanhui, Z. Zibin, Degradation process investigation of thermoplastic polyurethane elastomer in supercritical methanol. Polym Degrad Stab, 98(2013), 2520-2528.

[4] Zhu, P., Cao, Z. B., Chen, Y., Zhang, X. J., Qian, G. R., Chu, Y. L., and Zhou, M., Glycolysis recycling of rigid waste polyurethane foam from refrigerators. Environ Technol Environ Technol, 35(2014), 2676-84.

[5] D. Simón, M. T. García, A. de Lucas, A. M. Borreguero, and J. F. Rodríguez, Glycolysis of flexible polyurethane wastes using stannous octoate as the catalyst: Study on the influence of reaction parameters. Polym Degrad Stab, 98(2013), 144-149.

[6] Zhang S.L., Wang G.B., Jiang Z.H., Wu W.C., Ma R. T. and Wu Z. W., Melting and Crystallization Behavior of PA1010/TPU Blends. J. App. Polym. Sci., 94(2004):839-844.

[7] Hou L., Liu H, Yang G., Preparation and characterization of the moplastic polyurethane elastomer and polyamide 6 blends by in situanionic ring-opening polymerization of $\varepsilon$-caprolactam. Polym Engin Sci. 46(2006): 1196-1203.

[8] M.Z. Khalid, A.B. Ijaz, B. Mehdi, Z. Mohammad, N.B. Haq, XRD studies of polyurethane elastomers based on chitin/1,4-butane diol blends, Carbohyd. Polym., 76(2009):183-187. 